\title{
Frequent expression of the high molecular, 673-bp CD44v3,v8-10 variant in colorectal adenomas and carcinomas
}

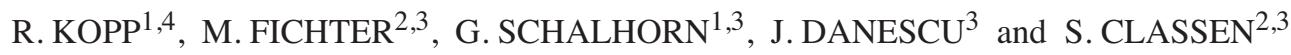 \\ Departments of ${ }^{1}$ Surgery; ${ }^{2}$ Clinical Ocology and Hematology, Klinikum Grosshadern, University of Munich, \\ Munich; ${ }^{3}$ GSF-National Research Center for Environment and Health, Munich; \\ ${ }^{4}$ Department of Surgery, Klinikum Harlaching, Munich, Germany
}

Received March 4, 2009; Accepted April 22, 2009

DOI: $10.3892 /$ ijmm_00000279

\begin{abstract}
CD44 is a transmembrane glycoprotein involved in the interaction between cells and the extracellular matrix. A large variety of alternatively spliced CD44 variants are expressed by different tumors with possible implication for tumor progression, formation of metastasis and survival. In colon carcinomas, previous reports described higher molecular bands of CD44 transcripts in neoplastic colonic tissue, although a complete analysis of multiple combinations of CD44v transcripts were not performed. We therefore analyzed the pattern of CD44 standard and variant (v2-v10) transcripts in colorectal adenomas and carcinomas by exon-specific RT-PCR amplification and sought CD44v transcripts specific for colonic neoplasias. Our data indicate that CD44 standard transcripts, including the epithelial form $(\mathrm{C}-\mathrm{v} 8, \mathrm{v} 9, \mathrm{v} 10-\mathrm{C})$ corresponding to a $720 \mathrm{bp}$ transcript, were detected in $2 / 38$ (5.2\%) samples of normal mucosa, 20/20 (100\%) adenomas and in 21/33 (63\%) colorectal carcinomas. High molecular CD44v3,v8-10 (673 bp) transcripts were found in 2/33 (6\%) samples from normal mucosa, 19/20 (95\%) from adenomas and in 29/31 from colorectal carcinomas (93\%). Similar CD44v3,v8-10 transcripts were detected in five from seven colorectal liver metastases, while normal liver did not contain high molecular CD44v3 variants. The same CD44v3,v8-10 (673 bp) variant was detected in HT-29 human colon carcinoma cells. Direct sequencing of the CD44v3 (673 bp) transcript in samples from colorectal carcinomas and HT-29 cells confirmed the assumed CD44v (-C-v3-v8-v9-v10-C-) cDNA sequence. Analysis of other CD44 variant transcripts (v4-v10) using exon specific primers were less frequently associated with colorectal neoplasias. These data report for the first time frequent
\end{abstract}

Correspondence to: Dr Reinhard Kopp, Department of Surgery, Klinikum Grosshadern, University of Munich, Marchioninistr 15, D-81377 Munich, Germany

E-mail: r.kopp@khmh.de

Abbreviations: RT-PCR, reverse transcriptase polymerase chain reaction; $\mathrm{CD} 44 \mathrm{v}, \mathrm{CD} 44$ variants

Key words: CD44v3, colorectal adenomas expression of neoplasia-associated CD44v3,v8-10 variants in colorectal adenomas and carcinomas supporting the role of increased CD44 variant expression as an early event in colorectal carcinogenesis. The described CD44v3,v8-10 (673 bp) variant might be relevant for diagnosis and treatment of colorectal cancer.

\section{Introduction}

The colonic adenoma-carcinoma sequence has been characterized by various changes in the expression of oncogenes, tumor suppressor genes, growth factors and DNA repair mechanisms (1-3). Adhesion molecules interacting with extracellular matrix molecules such as CD44 mediate interactions of the tumor cell with the microenvironment leading to tumor invasion and progression (4). The transmembrane glycoprotein CD44 and its splice variants are implicated in cell adhesion, proliferation, migration, tumor cell invasion and metastatic disease $(5,6)$.

CD44 is a transmembrane glycoprotein encoded by 20 exons, at least 10 of which are variably expressed due to alternative splicing (Fig. 1) (7). CD44 functions as a receptor for hyaluronic acid and elements of the extracellular matrix including laminin and fibronectin $(8,9)$. Furthermore, CD44 expression is involved in lymphocyte activation, hematopoiesis and stem cell differentiation (10). Alterations in the CD44 variant expression pattern were implicated to correlate with tumor progression and prognosis of patients with colorectal cancer (11). Besides the 360-bp CD44 standard form (CD44s), various CD44 variants $(\mathrm{CD} 44 \mathrm{v})$ were detected in several malignancies, including breast, lung and colon cancer (12-14).

The role of CD44 variants with the metastatic potential of tumor cells is supported by the introduction of a specific CD44 variant (CD44v6) into non-metastasatic pancreas carcinoma cells and the ability of distant tumor spread (15). The intravenous application of antibodies against CD44 prevented the development of distant metastasis following the injection of CD44 positive, highly metastatic melanoma cells (16).

Several studies have shown the presence of CD44 variants in colorectal cancer by immunohistochemistry and RT-PCR. However, analysis of the entire CD44 variant exons (v2-v10) and possible combinations of the different variants have not been reported in detail so far. Therefore, the present study investigated the expression of the CD44 standard form and the 
extracellular

transmembrane cytoplasmic region

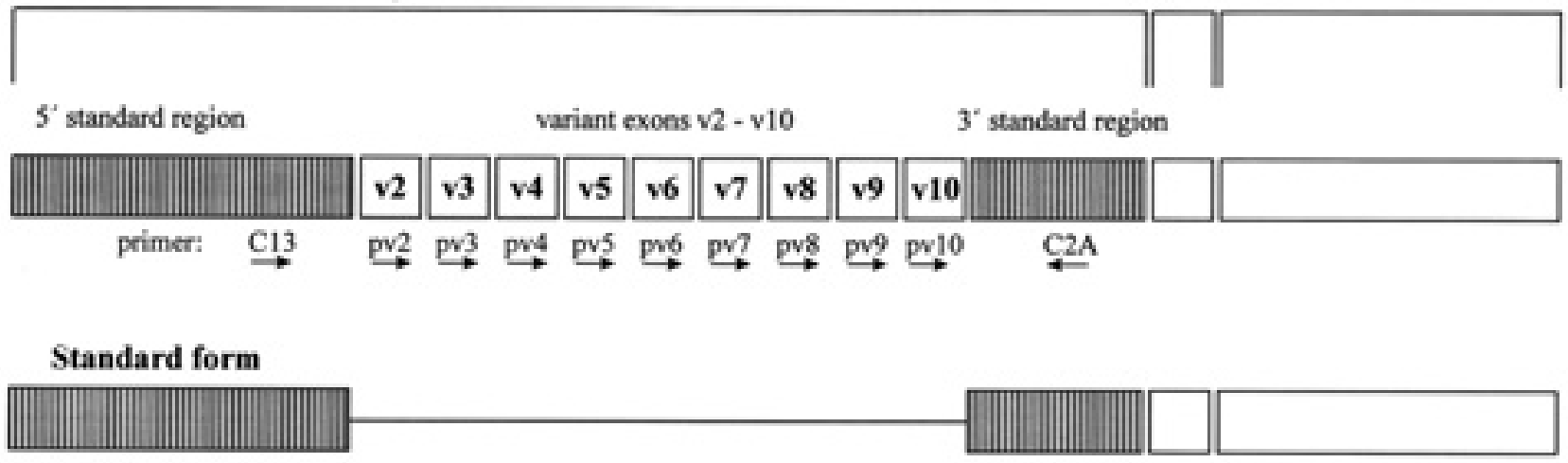

Epithelial form

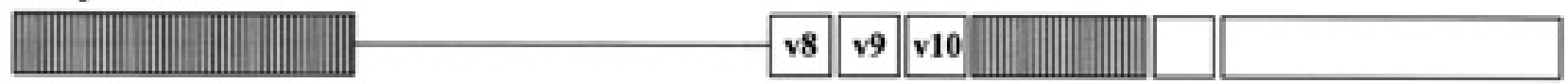

Carcinoma

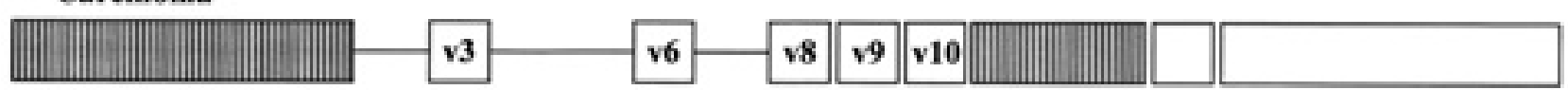

Figure 1. Human CD44 structure. A schematic presentation of the human CD44 structure with the variant region, the primer binding sites, the standard form without variant expression, the epithelial form and an example of a tumor CD44 variant composition is shown.

different CD44 variants in colorectal adenomas and carcinomas in comparison to histomorphologically normal mucosa.

\section{Materials and methods}

Patients and tissue samples. Tissue samples from 53 patients with colonic adenomas $(n=20)$ and carcinomas $(n=33)$, normal colonic mucosa $(n=38)$, liver metastasis from colon cancer $(n=7)$ and normal liver $(n=3)$ were investigated. Tissue probes of colonic adenomas were obtained following an endoscopic snare or surgical colon resection. Samples from colonic carcinomas were received following colonic resection according to the principles of oncologic surgery.

In patients with adenomas or carcinomas additional probes from normal appearing mucosa were taken as paired samples $10-20 \mathrm{~cm}$ away from the neoplastic lesion. Corresponding tissue probes were investiged by histopathological examination.

Tissue samples were immediately placed on ice and frozen in liquid nitrogen until further analysis was performed. Corresponding samples were transfered to histopathological examination. Diameter of adenomas $(n=20)$ ranged from 0.7 to $2.0 \mathrm{~cm}$ and were classified as a tubular adenoma $(\mathrm{n}=7)$ or a tubulovillous adenoma $(n=13)$ by histopathological examination.

Cell culture. HT-29 cells were obtained from the American Type Culture Collection (ATCC, Rockville, MD, USA). Cells were cultured in DMEM containing $2 \mathrm{mM}$ glutamine, $1 \mathrm{mM}$ pyruvate, $100 \mu \mathrm{g} / \mathrm{ml}$ penicillin/streptomycin and $200 \mathrm{IU} / \mathrm{ml}$ nystatin, supplemented with $6 \%$ fetal calf serum (Gibco) in $75 \mathrm{~cm}^{2}$ tissue culture flasks.

RNA isolation of cells and tissue samples. RNA from primary colorectal tumors, normal mucosa, adenomas, primary colo-
Table I. Oligonucleotide primers used for CD44 RT-PCR.

\begin{tabular}{lc}
\hline CD44 primers & Olignonucleotide sequence $\left(5^{\prime} \rightarrow 3^{\prime}\right)$ \\
\hline C13 & AAG ACA TCT ACC CCA GCA AC \\
pv2 & GAT GAG CAC TAG TGC TAC AG \\
pv3I & ACG TCT TCA AAT GAA GAA AA \\
pv4 & TCA ACC ACA CCA CGG GCT TT \\
pv5 & GTA GAC AGA AAT GGC ACC AC \\
pv6 & CAG GCA ACT CCT AGT AGT AC \\
pv7 & CAG CCT CAG CTC ATA CCA GC \\
pv8 & TCC AGT CAT AGT ACA ACG CT \\
pv9 & CAG AGC TTC TCT ACA TCA CA \\
pv10 & GGT GGA AGA AGA GAC CCA AA \\
C2A & CCA AGA TGA TCA GCC ATT CTG G
\end{tabular}

rectal carcinomas, normal liver and colorectal liver was purified by guanidium-thiocyanate-phenol extraction followed by isopropanol precipitation. Briefly cells and minced tissue samples were lysed directly with RNAzol B reagent (Tel-Test). Cellular protein and DNA was extracted with $1 / 10$ vol chloroform and centrifugation at $10,000 \mathrm{x}$ g. RNA was precipitated with $1 \mathrm{vol}$ 2-propanol and centrifuged at 10,000 x g. RNA pellets were washed once in $70 \%$ ethanol, air dried and resuspended in an appropriate volume of $\mathrm{H}_{2} \mathrm{O}$ at $65^{\circ} \mathrm{C}$.

RT-PCR amplification. Total cellular RNA was used as template for the synthesis of first strand cDNA with randomprimed oligonucleotide hexamers. The cDNA products were then used as templates for PCR as described $(17,18)$. 
Table II. Description of CD44 variant compositions detected in colonic tissues using variant specific primers.

\begin{tabular}{lccc}
\hline $\begin{array}{l}\text { PCR } \\
\text { primer }\end{array}$ & $\begin{array}{c}\text { Exon } \\
\text { composition }\end{array}$ & $\begin{array}{c}\text { Calculated } \\
\text { size (bp) }\end{array}$ & $\begin{array}{c}\text { Observed } \\
\text { size (bp) }\end{array}$ \\
\hline C13/C2A & C-C & 320 & 324 \\
& C-v8-v9-v10-C & 710 & 720 \\
pv3/C2A & C-v6-v8-v9-v10-C & 970 & 981 \\
& v3-C & 320 & 320 \\
pv4/C2A & v4-v5-v6-v7-v8-v9-v10-C & 1010 & 673 \\
pv5/C2A & v5-C & 320 & 320 \\
& v5-v6-v7-v8-C & 730 & 721 \\
pv6/C2A & v5-v8-v9-v10-C & 800 & 796 \\
& v6-v7-v8-C & 520 & 514 \\
& v6-v7-v8-v9-C & 610 & 604 \\
pv8/C2A & v6-v7-v8-v9-v10-C & 820 & 808 \\
& v8-v9-C2A & 330 & 337 \\
& v8-v9-v10-C2A & 535 & 541 \\
\hline
\end{tabular}

Amplifications were carried out with an initial cycle (2 min at $94^{\circ} \mathrm{C}, 1 \mathrm{~min}$ at $55^{\circ} \mathrm{C}$ and $2 \mathrm{~min}$ at $72^{\circ} \mathrm{C}$ ) followed by 30 cycles each $45 \mathrm{sec}$ at $94^{\circ} \mathrm{C}, 1 \mathrm{~min}$ at $55^{\circ} \mathrm{C}$ and $1 \mathrm{~min}$ at $72^{\circ} \mathrm{C}$ using a Biometra Uno Thermocycler (Biometra, Göttingen, Germany). The oligonucleotide primer pair $\mathrm{C} 2 \mathrm{~A}$ and $\mathrm{C} 13$ hybridizes to the constant region of CD44 flanking the alternatively spliced exons. Eight more primers (pv3, 4, 5, 6, 7, 8, 9, 10), each specific to one of the alternatively spliced exons were used for amplification of CD44 variants (Table I). PCR reactions were performed under mineral oil in a total volume of $50 \mu 1$. To check for RNA and cDNA quality, a portion of the constitutively expresssed housekeeping gene, glycerin-aldehydphosphate-dehydrogenase (GADPH), was amplified along with the probes. PCR products were seperated on $1.4 \%$ agarose gel, stained with ethidium bromide and photographed with a video camera. The possible combinations of CD44 variants and the calculated and observed CD44 variant compositions are given in Table II.

Sequence-analysis. For sequencing of distinct PCR-products DNA bands were cut from agarose gel and analyzed by cycle sequencing. Linear amplification was performed in a thermal cycler for 20 cycles using fluorescent dye-labeled primers followed by automated flourescence sequencing using an ABI-sequencer.

Data analysis. For comparison of frequencies chi-squared analysis was used. A p-value of $<0.05$ was considered statistically significant.

\section{Results}

Expression of different CD44 variants was investigated in tissue samples from 20 patients with colonic adenomas, 33 patients with colorectal carcinomas and 3 patients with liver metastasis. Normal colorectal mucosa and normal liver were used as control for comparison with neoplastic tissue samples.

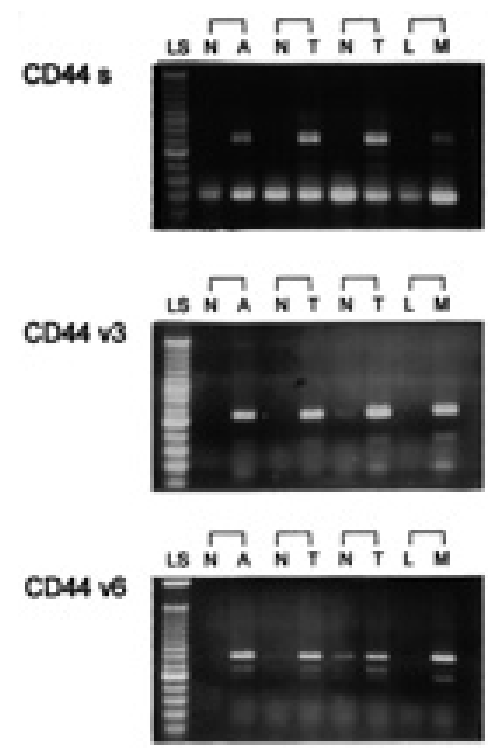

Figure 2. CD44 standard and variant RT-PCR transcripts detected in colorectal neoplasias and metastasis. CD44 variants were investigated in indicated samples of human colonic mucosa $(\mathrm{N})$, colonic adenoma (A), colonic carcinoma $(\mathrm{T})$, normal liver and liver metastasis (M). CD44s indicates the CD44 standard form either without variant expression (324 bp) or the CD44 standard form together with the epithelial form (720 bp). Analysis of CD44v3 transcripts showed predominant expression of the CD44v3,8-10 (673 bp) variant in neoplastic colonic tumor probes and metastasis. RT-PCR amplification using primers specific for CD44v6 showed neoplasia-associated high molecular transcripts with different CD44 variant compositions $(808,604$ and 514 bp).

The CD44 standard form, without additional variant exons corresponding to a 360-bp RT-PCR transcript, was expressed in every normal colonic mucosa and in every adenoma or carcinoma sample. Using the same CD44 primers to amplify the whole variant region, another 720-bp transcript was frequently expressed, corresponding to the so called 'epithelial form' and was identified in 2/38 (5.2\%) samples of normal mucosa, 20/20 $(100 \%, \mathrm{p}<0.001)$ colonic adenomas and in $21 / 33(63 \%, p<0.01$, both in comparison to normal mucosa) colonic carcinomas (Fig. 2, Table III). CD44v2 containing transcripts were not detected in any of the normal or neoplastic colonic tissues investigated.

The single CD44v3 variant (320 bp) was weakly expressed in the normal colonic mucosa of four patients. Higher molecular CD44v3 (673 bp) transcripts were frequently detected in colorectal neoplasias representing a combination of the CD44v3 variant and the epithelial form, including variants v8-v10 (Fig. 2). These CD44v3,v8-v10 transcripts were detected in $2 / 33(6 \%)$ samples from normal mucosa, 19/20 (95\%, $\mathrm{p}<0.001)$ from adenomas and in 29/31 samples from colorectal carcinomas $(93.5 \%, \mathrm{p}<0.001$, both in comparison to normal mucosa; Table III). Similar CD44v3,v8-10 transcripts were detected in 5 out of 7 colorectal liver metastases, while normal liver did not contain high molecular CD44v3 variants. The same CD44v3,v8-10 (673 bp) variant was detected in HT-29 human colon carcinoma cells (Fig. 3). Direct sequencing of the detected high molecular CD44v3 (673 bp) transcript confirmed the assumed CD44v (-C-v3-v8-v9-v10-C-) transcript with $>98 \%$ homology to the known human CD44v cDNA sequence (Fig. 4). 
Table III. CD44 RT-PCR transcripts detected in normal colonic mucosa, colorectal adenomas and carcinomas.

\begin{tabular}{|c|c|c|c|c|c|c|c|c|c|}
\hline CD44 & $\begin{array}{c}\text { std } \\
(320 \text { bp) }\end{array}$ & $\begin{array}{c}\text { v3 } \\
(673 \mathrm{bp})\end{array}$ & $\begin{array}{c}\text { v4 } \\
(1039 \text { bp) }\end{array}$ & $\begin{array}{c}\text { v5 } \\
\text { (925 bp) }\end{array}$ & $\begin{array}{c}\text { v6 } \\
\text { (808 bp) }\end{array}$ & $\begin{array}{c}\text { v7 } \\
(700 \text { bp) }\end{array}$ & v8 & v9 & v10 \\
\hline Normal mucosa & $\begin{array}{l}38 / 38 \\
100 \%\end{array}$ & $\begin{array}{c}2 / 33 \\
6 \%\end{array}$ & $\begin{array}{r}0 / 32 \\
0 \%\end{array}$ & $\begin{array}{l}1 / 35 \\
3 \%\end{array}$ & $\begin{array}{c}5 / 38 \\
13 \%\end{array}$ & $\begin{array}{c}16 / 35 \\
46 \%\end{array}$ & $\begin{array}{r}24 / 29 \\
83 \%\end{array}$ & $\begin{array}{c}4 / 6 \\
67 \%\end{array}$ & $\begin{array}{r}10 / 11 \\
91 \%\end{array}$ \\
\hline Adenoma & $\begin{array}{l}20 / 20 \\
100 \%\end{array}$ & $\begin{array}{c}19 / 20^{\mathrm{a}} \\
95 \%\end{array}$ & $\begin{array}{l}8 / 15 \\
53 \%\end{array}$ & $\begin{array}{l}18 / 20 \\
90 \%\end{array}$ & $\begin{array}{l}17 / 19 \\
89 \%\end{array}$ & $\begin{array}{c}13 / 17 \\
76 \%\end{array}$ & $\begin{array}{l}13 / 13 \\
100 \%\end{array}$ & $\begin{array}{c}8 / 9 \\
89 \%\end{array}$ & $\begin{array}{l}14 / 14 \\
100 \%\end{array}$ \\
\hline Carcinoma & $\begin{array}{l}33 / 33 \\
100 \%\end{array}$ & $\begin{array}{c}29 / 31^{\mathrm{a}} \\
94 \%\end{array}$ & $\begin{array}{l}8 / 30 \\
27 \%\end{array}$ & $\begin{array}{l}12 / 30 \\
40 \%\end{array}$ & $\begin{array}{c}14 / 32 \\
44 \%\end{array}$ & $\begin{array}{c}22 / 28 \\
79 \%\end{array}$ & $\begin{array}{r}13 / 30 \\
43 \%\end{array}$ & $\begin{array}{c}4 / 8 \\
50 \%\end{array}$ & $\begin{array}{l}8 / 10 \\
80 \%\end{array}$ \\
\hline
\end{tabular}

Shown are CD44 transcripts obtained after RT-PCR amplification using specific primers for amplification of CD44 standard or variant transcripts. The numbers of the detected CD44 standard form (320 bp), the frequencies of high molecular weight CD44 transcripts (CD44v3, v4, v5, v6, v7 variants) and CD44 transcripts of the epithelial form (v8, v9 or v10) are also indicated. ${ }^{\mathrm{a}} \mathrm{P}<0.001$.

Analysis of high molecular variants including CD44v4, v5, v6 and v7 transcripts showed less frequent expression of these variants in colorectal adenomas (v4, 53\%; v5, 90\%; v6, $89 \%$; v7, 76\%) and carcinomas (v4, 27\%; v5, 40\%; v6, 44\%; v7, 79\%), as shown in Table III. The predominantly detected CD44v4-v7 variant compositions following RT-PCR amplification using specific CD44 variant were: -v4 primer, v4-v5-v6-v7-v8-v9-10 (1,039 bp); -v5 primer, v5-v6-v7-v8v9-10 (925 bp); -v6 primer, v6-v7-v8-v9-10 (808 bp); -v7 primer, v7-v8-v9-v10 (700 bp); -v8 primer, v8-v9-v10 (541 bp). Other smaller CD44 transcripts were less frequently detected and not associated with colonic neoplasias.

Transcripts of the CD44v8-v10 variant (epithelial form, 720 bp) were analyzed using CD44v8, v9 and v10 primers. This variant was expected to be expressed with high frequency in intestinal epithelial cells. As shown in Table III, CD44v8, v9 and v10 transcripts were found in normal colonic mucosa (v8, 83\%; v9, 67\%; v10, 91\%), adenomas (v8, 100\%; v9, $89 \%$; v10, 100\%) and carcinomas (v8, 43\%; v9, 50\%; v10, $80 \%$ ) with varying and lower frequencies in colonic carcinomas. Five from seven samples of liver metastases from colorectal cancer analyzed were positive for amplification of CD44v8, v9 and v10 transcripts, while normal liver was negative.

\section{Discussion}

CD44 is a transmembrane glycoprotein involved in the interaction between cells and the extracellular matrix with implications of cell migration, malignant transformation and the metastatic potential of tumor cells $(10,19)$. In the present study we investigated the expression of CD44 standard transcripts, different CD44 variants and possible CD44 combinations in colorectal adenomas or carcinomas and sought for a distinct CD44 expression pattern associated with colorectal neoplasias. The reported data indicate, that the most specific and sensitive marker associated with colorectal neoplasias was the CD44v3 (673 bp) transcript, corresponding to a CD44 variant combination including variants $\mathrm{v} 3, \mathrm{v} 8$, v9 and $\mathrm{v} 10$.

So far, several studies reported higher molecular forms of CD44 variants expressed in colorectal adenomas and carcinomas $(20,21)$, although a detailed analysis of specific tumor-asociated CD44 variant combinations has not been

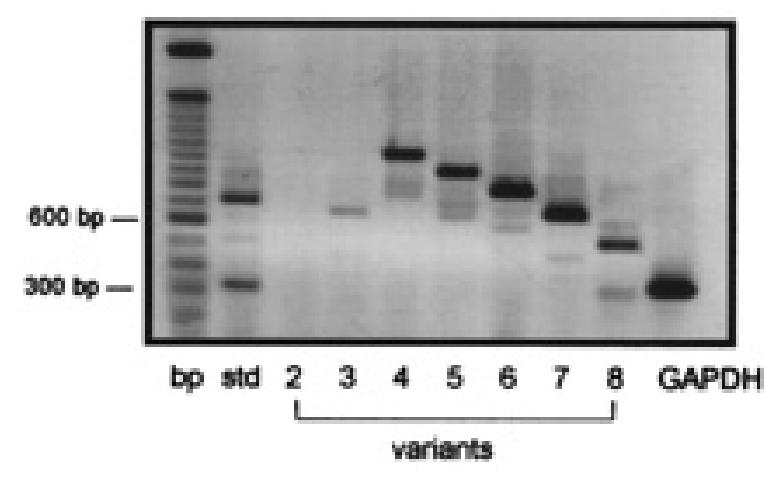

Figure 3. CD44 standard and variant transcripts determined in HT-29 human colon carcinoma cells. CD44 variant expression was analyzed in HT-29 cells after RT-PCR amplification using CD44 variant specific primers.

performed. Dall et al (22) isolated tumor mRNA from uterine cervical carcinomas corresponding to CD44 variants containing the variant exons v3-v10. The CD44v3 (673 bp) transcript described in our study contains the combination of the CD44 variant v3 and variants v8-v10 (epithelial form). These findings are supported by additional studies performed by our group in tumor samples from patients with gastric carcinomas in which we also detected the described CD44v3,v8-v10 (673 bp) variant, especially in intestinal-type gastric cancer samples, according to the Lauren classification (data not shown). In contrast, the analysis of tissue samples from patients with breast cancer, renal cancer and nasopharyngeal cancer were negative for the described CD44v3,v8-10 (673 bp) transcripts. In addition, further analysis of different cell lines including breast cancer cells (MCF-7, T417), neuroblastoma cells (SK-N-SH) and normal human peripheral blood cells did not show a similar CD44v3 (673 bp) variant, either in unstimulated cells or after incubation with hormones, growth factors or phorbol ester. In the present study, analysis of CD44 v8, v9 and v10 transcripts showed relevant variations with frequencies between 43 and $80 \%$, especially in samples of colonic carcinomas. According to the high expression of these CD44 variants in colonic adenomas we exclude problems with the CD44 variant primers or the method of RT-PCR amplification used. However, the lower frequencies of the CD44v8-v10 variants expressed in colonic carcinomas in 
v

b-CD44 requerex:

5 . HT29 colea carcinoma cellit.

5.489 colon cancer
CGI CII CAA ATA CCA TC̈ CAG CAG GCT GCG ACC CAA ATO AAG AAAATG AAG ATG AAAGAG PCR primer binding region PCR primet bisding rtgioe

\section{G AAA ATG AMT AT AAT EAT}

vs

h-CD44: ACAGACACCTCA GTT TT CTG GAT CAG GCATTG ATG ATG ATG AAGATI TIA TCT CCA GCA CCA ATA TGG ACT CCA GTC ATAGTA

5' HTA9 ACA GAC AOC TCA GTT TTT CTG GAT CAG GCA TTG ATG ATG ATO AAG ATT TTA TCT CCA GCA CCA ATA TGG ACT CCA GTC ATA GTA

5. 689 AGA NAC ACC TCA TIT TTT CTG GAT CAG GCA TTG ATG ATG ATG AN ATT TTA TCT CCA GCA OCA ATA TOG ACT CCA NTC ATN GTA

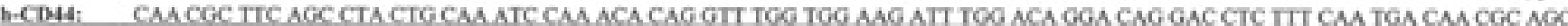

5. HT2\%: CAA COC TTC GGC CTA CTO CAA ATC CAA ACA CAG GTT TGG TGG AAG ATT TCG ACA GGA CNG GAC CTC TTT CAA TGA CAA CGC AGC

S' 4991 CAA CNC TTC GGC CTA CTG CAA ATC CAA ACA CAO GTT TOO TGO AAG ATT TOG ACA GGA CNG GAC CTC NTT CAA TGA CAA CGC AGC

b-CD44: AGAGTA ATI CTC AGAGCT TCT CTA CAT CAC ATG AAG CCT TGQAAG AMG ATA AMG ACC ATC CAACAACTI CTACTC TGA CAT

5' HT29: AGA GTA ATT CTC AGA GCT TCT CTA CAT CAC ATG AAG CCT TGG AAG NAG ATA AAG NOC ATC CAA CAA CTT CTA CTC TGA CAT

5' 699; DGA GTA ATT CTC MGA GCT TCT CTA CAT CAC ATG ANG GCT TOG AAG AAG ATA AAG ACC ATC CAA CAA CTT CTA CTC TGA CAT V10

H.CD44: CAAGCAATA GGA ATGATG TCACAG OTGGAA OAAGAGACC CAAATC ATT CTG AAG GCT CAACTACII TAC TGGAAGGII

5' HT2: CAA GCA ATA GGA ATG ATG TCA CAG GTG GAA GAA GAG ACC CAA ATC ATT CTG AAO GCT CAA CTA CTT AAC TCG AAG GTT

5' 699: CAA GCA ATA GGA ATG ATG TCA CAG GTG GAA GA GAG ACC CAA ATC ATT CTG AAG GCT CAA CTA CTT NMC TGG AAG GTT

h-CD44: ATA CCT CTC ATT ACC CACACA COA AGOAAA OCA GOA CCT TCA TOC CAG TGA CCT CAG CTA AGA CTG GGT CCT TITG GAG TI

5' IIT29: ATA CCT CTC NTT ACC CAC ACA CGA AGG AAA GCA GGA CCT TCA TOC CAG TOA CCT CAG NTA AGA CTG GGT CCT TNG GAG TTA

5. 699: ATA CCT CTC NTT ACC CAC ACA COA NGG AAA GCA GGA CCT TCA TOC CAG TGA CCT CAG NTA AGA CTG GGT CCT TNGG GAG TTA

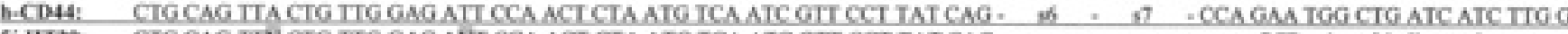

5' HT2\%: CTG CAG TTN CTG TTG GAG ANT CCA ACT CTA ATG TCA ATC GTT CCT TAT CAG .............. . . PCR primer binding nepion

5. 689: CTG CAG TTA CTG TTG GAG ATT CCA ACT CTA ATG TCA ATC GTT CCT TAT CAG ................ .

Figure 4. Sequencing of CD44 RT-PCR transcripts. Sequence of the CD44v3 (673 bp) PCR-transcript found in HT-29 human colon carcinoma cells and in a representative human colon cancer sample, compared to the known human CD44 squence (h-CD44). Single nucleotide exchanges and unresolved nucleotide sequencing data are shown in light grey.

comparison to normal mucosa will exclude these variants from possible use for diagnostic assays or therapeutic concepts.

Prognostic implications of CD44v3 in colorectal cancer as analyzed by immunohistochemistry were reported by Ropponen et al (23). In samples of colonic mucosa from patients with colitis ulcerosa, Rosenberg et al reported positive CD44v3 immunoreactivity, while this variant was not detectable in the mucosa of patients with Chrohn's disease (24). In our study, we also found the described CD44v3 (675 bp) transcript in a lymph node sample from a patient with acute diverticulitis, indicating an expression of the CD44v3 (673 bp) transcript in association with inflammation. However, Hofmann et al (1991) described in HT-29 cells only one isoform containing the epithelial form (v8-v10) (25). In addition, an earlier study Heider et al, investigated CD44v3 immunoreactivity in colonic adenomas and carcinomas and did not find epitopes corresponding to CD $44 \mathrm{v} 3$ variants in colorectal neoplasias (26). The authors concluded that these distinct epitopes are masked on larger CD44 proteins.

The regulation of CD44 variant expression involves specific splicing factors, RAS/MAPK signalling and intracellular kinases including protein kinase $\mathrm{C}$ and c-Jun N-terminal kinase (JNK) $(27,28)$. We previously showed, that the expression of CD44 variant isoforms is stimulated by growth factors like PDGF or IGF-I and regulated by phospho-inositide 3-kinase and protein kinase $\mathrm{C}$ in SK-N-SH human neuroblastoma cells (18). Recently, we reported, that sodium butyrate, a potent HDAC inhibitor, known to regulate intestinal epithelial cell proliferation and differentiation, reduced the expression of high molecular CD44v3, v5 and v8 variants in HT-29 colon carcinoma cells (29). Similar findings were reported by Barishat et al in HM7 colon carcinoma cells showing decreased expression of CD44 variants and reduced metastatic potential following butyrate treatment, indicating an association of CD44 variant overexpression with hyperproliferative and undifferentiated cells (30). In addition, in HeLa cells, non-mutant ras signalling was shown to promote CD44v6 splicing and CD44v6 then sustained late ras signalling indicating a positive feedback loop (31).

Little is known about the cellular function of CD44 variants in neoplastic cells. Probably the tumor cells are able to escape from the detection by immune cells due to the similar pattern of CD44 epitopes expressed on tumor cells and lymphocytes. In addition, an increased binding to components of the extracellular matrix might facilitate the invasion of tumor cells and CD44 was reported to promote resistance to apoptosis in colon cancer cells $(9,32,33)$. Data from leukemia cells transfected with various CD44 variants showed, that cells expressing the CD44v3 variant show increased binding sites for heparin binding epidermal growth factor (HB-EGF) and basic fibroblast growth factor (b-FGF), known to stimulate autocrine tumor cell growth and angiogenesis (34). Co-expression of heparanase and CD44v3 was shown to be correlated with a more advanced, invasive and metastatic colon cancer disease (35). Recently, colonic cancer stem cells were characterized by specifc CD133 and CD44 expression, although the CD44 variant expressed in cancer stem cells associated with colon cancer have not yet been further analyzed (36). CD44 variant expression on colonic intraepithelial stem cells plays an important role in WNT mediated induction of carcinogenesis of colonic epithelial cells (37).

In addition to the reported involvement of CD44 variants in colorectal carcinogenesis, CD44 variant expression might be associated with possible prediction of antitumor response and represents a target for new anticancer therapies. According to the data from Bates et al (38) CD44 variant expression seems to be involved in the induction of chemoresistance via activation of Lyn kinase and phosphoinositide 4-kinase/Akt 
pathways. New therapeutic strategies targeting CD44 variant expression using CD44 antisense cDNA or transfection and intratumoral application of constructs producing silencing (si)RNA against the transmembrane region of CD44 exons were reported to show inhibition of tumor growth and reduced tumor volume in colon carcinoma xenograft model systems $(39,40)$. In addition, adenoviral (AAV)-mediated gene therapy requires specific binding to tumor cells via heparan proteoglycan and b-FGF binding sites, which are detected on CD44v3 variant molecules (41). Therefore, CD44v3 variant expression on tumor cells might indicate specific targets for new antitumor strategies.

In summary, the reported analysis of distinct high molecular combinations of CD44 variant transcripts showed a differential expression pattern in samples from colonic normal mucosa, adenomas and colonic carcinomas. The described CD44v3 (673 bp) transcripts are an interesting candidate for specific diagnostic assays in patients with colorectal cancer and additionally represent a possible target for new site-directed antitumor strategies.

\section{Acknowledgement}

The authors wish to thank T. Kröll and E. Doischer for excellent technical assistence.

\section{References}

1. Fearon ER and Vogelstein B: A genetic model for colorectal tumorigenesis. Cell 61: 759-767, 1990.

2. Segditsas S and Tomlinson I: Colorectal cancer and genetic alterations in the Wnt pathway. Oncogene 25: 7531-7537, 2006.

3. Al-Sukhni W, Aronson M and Gallinger S: Hereditary colorectal cancer syndromes: familial adenomatous polyposis and lynch syndrome. Surg Clin North Am 88: 819-844, 2008.

4. Ladeda V, Aquirre Ghiso JA and Bal de Kier Joffe E: Function and expression of CD44 during spreading, migration, and invasion of murine catcinoma cells. Exp Cell Res 242: 515-527, 1998

5. Herrlich P, Pals S and Ponta H: CD44 in colon cancer. Eur J Cancer 31 (Suppl A): 1110-1112, 1995.

6. Kim H, Yang XL, Rosada C, Hamilton SR and August JT: CD44 expression in colorectal adenomas is an early event occuring prior to K-ras and p53 gene mutation. Arch Biochem Biophys 310: 504-507, 1994.

7. Tölg C, Hofmann M, Herrlich P and Ponta H: Splicing choice from ten variant exons establishes CD44 variability. Nucleic Acid Res 21: 1225-1229, 1993.

8. Isacke CM and Yarwood H: The hyaluronan receptor, CD44. Int J Biochem Cell Biol 34: 718-721, 2002.

9. Ponta H, Sherman L and Herrlich PA: CD44: from adhesion molecules to signalling regulators. Nat Rec Mol Cell Biol 4: $33-45,2003$

10. Heldin P, Karousou E, Bernert B, Porsch H, Nishitsuka K and Skandalis SS: Importance of hyaluronan-CD44 interaction in inflammation and tumorigenesis. Connect Tissue Res 49: 215-218, 2008.

11. Mulder JWR, Kruyt PM, Sewnath M, Oosting J, Seldenrijk CA, Weidema WF, Offerhaus GJA and Pals ST: Colorectal cancer prognosis and expression of exon-v6-containing CD44 proteins. Lancet 344: 1470-1472, 1994.

12. Friedrichs K, Franke F, Lisboa BW, Zügler G, Gille I, Terpe HJ, Hölzel F, Maass H and Günthert U: CD44 isoforms correlate with cellular differentiation but not with prognosis in human breast cancer. Cancer Res 55: 5424-5433, 1995.

13. Jackson DG, Schenker T, Waibel R, Bell JI and Stahel RA: Expresssion of alternatively spliced forms of the CD44 extracellular-matrix receptor on human lung carcinomas. Int J Cancer (Suppl) 8: 110-115, 1994.

14. Wielenga VJM, Heider KH, Offerhaus GJA, Adolf GR, van den Berg FM, Ponta H, Herrlich P and Pals ST: Expresssion of CD44 variant proteins in human colorectal cancer is related to tumor progression. Cancer Res 53: 4754-4756, 1993.
15. Günthert U, Hofmann M, Rudy W, Reber S, Zöller M, Haussmann I, Matzku S, Wenzel A, Ponta H and Herrlich P: A new variant of glycoprotein CD44 confers metastatic potential to rat carcinoma cells. Cell 65: 13-24, 1991.

16. Sy MS, Guo YJ and Stamenkovic I: Inhibition of tumor growth in vivo with a soluble CD44-immunglobulin fusion protein. J Exp Med 176: 623-627, 1992.

17. Van Weering DHJ, Baas PD and Bos L: A PCR-based method for the analysis of human CD44 splice products. PCR Methods Appl 3: 100-106, 1993.

18. Fichter M, Hinrichs R, Eissner G, Scheffer B, Classen S and Ueffing M: Expression of CD44 isoforms in neuroblastoma cells is regulated by PI 3-kinase and protein kinase C. Oncogene 14: 2817-2824, 1997.

19. Fox SB, Fawcett J, Jackson DG, Collins I, Gatter KC, Harris AL, Gearing A and Simmons DL: Normal human tissues, in addition to some tumors, express multiple different CD44 isoforms. Cancer Res 54: 4539-4546, 1994.

20. Imazeki F, Yokusuka O, Yamaguchi T, Ohto M, Isono $\mathrm{K}$ and Omata M: Expression of variant CD44-messenger RNA in colorectal adenocarcinomas and adenomatous polyps in humans. Gastroenterology 110: 362-368, 1997.

21. Wielenga VJ, van der Voort R, Taher TE, Smit L, Beuling EA, van Krimpen C, Spaargaren M and Pals ST: Expression of c-Met and heparan-sulfate proteoglycan forms of CD44 in colorectal cancer. Am J Pathol 157: 1563-1673, 2000.

22. Dall P, Heider KH, Hekele A, von Minckwitz G, et al: Surface protein expression and messenger RNA-splicing analysis of CD44 in uterine cervical cancer and normal cervical epithelium. Cancer Res 54: 3337-3341, 1994.

23. Ropponen KM, Eskelinen MJ, Lipponen PK, Alhava E and Kosma AV: Expression of CD44 and variant proteins in human colorectal cancer and its relevance for prognosis. Scand J Gastroenterol 33: 301-309, 1998.

24. Rosenberg WMC, Prince C, Kaklamanis L, Fox SB, Jackson DG, Simmons DL, Chapman RW, Trowell JM, Jewell DP and Bell JI: Increased expression of CD44v6 and CD44v3 in ulcerative colitis but not colonic Crohn's disease. Lancet 345: 1205-1209, 1995.

25. Hofmann M, Rudy W, Günthert U, Zimmer GS, Zawadzki V, Zöller M, Lichtner RB, Herrlich P and Ponta H: A link between ras and metastatic behavior of tumor cells: ras induces CD44 promoter activity and leads to low-level expression of metastatic specific variants of CD44 in CREF cells. Cancer Res 53: 1516-1521, 1993.

26. Heider KH, Hofmann M, Hors E, van den Berg F, Ponta H, Herrlich P and Pals ST: A human homologue of the rat metastasisassociated variant of CD44 is expressed in colorectal carcinomas and adenomatous polyps. J Cell Biol 120: 227-233, 1993.

27. Jamal HH, Cano-Gauci DF, Buick R and Filmus J: Activated ras and src induce CD44 overexpression in rat intestinal epithelial cells. Oncogene 9: 417-423, 1994.

28. Cheng $C$ and Sharp PA: Regulation of CD44 alternative splicing by Srm160 and its potential role in tumor cell invasion. Mol Cell Biol 26: 362-370, 2006.

29. Kopp R, Fichter M, Assert R, Pfeiffer AF and Classen S: Butyrate-induced alterations of phosphoinositide metabolism, protein kinase $\mathrm{C}$ activity and reduced CD44 variant expresion in HT-29 colon cancer cells. Int J Mol Med 23: 639-649, 2009.

30. Barishat M, Levi I, Benharroch D and Schwartz B: Butyrate down-regulates CD44 transcription and liver colonisation in a highly metastatic human colon carcinoma cell line. Br J Cancer 87: 1314-1320, 2002.

31. Cheng C, Yaffe MB and Sharp PA: A positive feedback loop couples ras activation and CD44 alternative splicing. Genes Dev 20: 1715-1720, 2006

32. Lakshman M, Subramaniam V, Rubenthiran U and Jothy S: CD44 promotes resistance to apoptosis in human colon cancer cells. Exp Mol Pathol 77: 18-25, 2004

33. Kuniyasu H, Oue N, Sutsumi M, Tahara E and Yasui W: Heparan sulfate enhances invasion by human colon carcinoma cell lines through expression of CD44 variant exon 3. Clin Cancer Res 7: 4067-4072, 2001.

34. Benett KL, Jackson DG, Simon JC, Tanczos E, Peach R, Mdrell B, Stamenkovic I, Plowman G and Aruffo A: A CD44 isoform containing exon $\mathrm{v} 3$ are responsible for the presentation of heparin-binding growth factor. J Cell Biol 128: 687-698, 1995.

35. Kuniyasu H, Chihara Y, Kubozoe T and Takahashi T: Coexpression of CD $44 \mathrm{v} 3$ and heparanase is correlated with metastasis of human colon cancer. Int J Mol Med 10: 333-337, 2002. 
36. Du L, Wang H, He L, Zhang J, Ni B, Wang X, Jin H, Cahuzac N, Mehrpour M, Lu Y and Chen Q: CD44 is of functional importance for colorectal cancer stem cells. Clin Cancer Res 14: 6751-6760, 2008.

37. Zeilstra J, Joosten SP, Dokter M, Verwiel E, Spaargaren M and Pals ST: Deletion of the WNT target and cancer stem cell marker $\mathrm{CD} 44$ in Apc(Min/+) mice attenuates intestinal tumorigenesis. Cancer Res 68: 3655-3661, 2008

38. Bates RC, Edwards NS, Burns CF and Fisher DE: A CD44 survival pathway triggers chemoresistance via lyn kinase and phosphoinositide 3-kinase/Akt in colon carcinoma cells. Cancer Res 61: 5275-5283, 2001.
39. Harada N, Mizoi T, Kinouchi M, Hoshi K, Ishii S, Shiiba K, Saaki I and Matsuno S: Introduction of antisense CD44s cDNA down-regulates expression of overall isoforms and inhibits tumor growth and metastasis in highly metastatic colon carcinomas cells. Int J Cancer 91: 67-95, 2001.

40. Subramaniam V, Vincent IR, Galikjan M and Jothy S: Suppression of human colon cancer tumors in nude mice by siRNA CD44 gene therapy. Exp Mol Pathol 83: 332-340, 2007.

41. Smith A, Collaco R and Trempe JP: AAV vector delivery to cells in culture. Meth Mol Biol 246: 167-177, 2004. 